\title{
LETTERS
}

\section{We must also think about trainees and the role of culture in physician mental health}

Drs. Albuquerque and Tulk should be commended for covering an incredibly complex and salient topic in health care: that of physician suicide. ${ }^{1}$ We're only beginning to discuss this openly, and greater awareness is needed.

However, a conversation about suicidality in the medical profession would be incomplete without mention of a recent survey showing that as many as $78 \%$ of trainees have experienced bullying and harassment. ${ }^{2}$ The evidence currently points to the learning environment in medical training as being an important contributor to this. ${ }^{3}$ Doctors, by their very nature, are incredibly resilient, ${ }^{4}$ leading some to state flatly that "resident wellness is a lie." We deal with life and death every day and jump through many hoops to gain admission into the prestigious and competitive field.

Some factors behind the uptick in depression, anxiety, burnout and suicidality cannot be controlled: the long work hours, high expectations and poor sleep, for instance. However, other factors can be: issues such as the culture in the learning environment, prevalence of bullying and harassment, and the presence of policies to protect learners from psychological harm that ensue from these factors, as well as protection from reprisal when reporting concerns.
We believe many of these latter factors can be ameliorated with sound leadership in programs: for instance, choosing and supporting leaders who govern wisely, with integrity and compassion and who are, ideally, elected democratically by the trainees they are intended to serve. As well, we believe that the cornerstone of an effective "physician health program" must be free of any conflict of interest personal or financial - that places the managers of the program in a position of serving 2 masters: the trainee and the program or medical school.

We hope readers will be engaged in these issues and understand that the quest for physician wellness goes far beyond the basics of resilience training. Instead, physician wellness must start with "boots on the ground": shifts in culture that have far more to do with organizational leadership, psychology and vulnerability.

The profession is at a tipping point in terms of grappling with these issues. As millennial physicians who are committed to the issue of trainee well-being in the context of the learning and work environment, ${ }^{6,7}$ and who believe in the promise of medical training, we strongly urge trainees and physicians to be vigilant of the systemic institutional issues affecting them locally, and to seek leadership roles in order to drive change. Medicine, to paraphrase the words of Brené Brown, needs leaders who lead with courage, vulnerability and compassion. ${ }^{8}$ We commend CMAJ for helping shed light on the dire consequences that may result if we continue to turn a blind eye.

\section{Amitha Kalaichandran MD}

Resident physician

Ottawa, Ont.

\section{Daniel Lakoff MD}

Attending physician and associate residency program director, Emergency Medicine, Mount Sinai Hospital; cofounder, National Physician Suicide Awareness Day

New York City, NY

Cite as: CMAJ 2019 September 9; 191:E1009. doi: 10.1503/cmaj.72749

\section{References}

1. Albuquerque J, Tulk S. Physician suicide. CMAJ 2019;191:E505.

2. 2018 National Resident Survey. Ottawa: Resident Doctors of Canada; 2018. Available: https:// residentdoctors.ca/publications/national-resident -survey/nrs-2018/ (accessed 2019 May 10).

3. Pereira-Lima K, Gupta RR, Guille C, et al. Residency program factors associated with depressive symptoms in internal. medicine interns: a prospective cohort study. Acad Med 2019;94:869-75.

4. Balme E, Page L. Doctors need to be supported, not trained in resilience. BMJ 2015;351:h4709.

5. Bernstein JR. Resident wellness is a lie (part 1 of 3 ). in-House 2019 Feb. 28. Available: https://in -housestaff.org/resident-wellness-is-a-lie-part -1-1319 (accessed 2019 May 10).

6. Kalaichandran A. In America, becoming a doctor can prove fatal. Boston Globe 2019 Mar. 15. Available: www.bostonglobe.com/ideas/2019/03/15/ america-becoming-doctor-can-prove-fatal/ u3x4xfPC9VR2zSCnKArgYM/story.html (accessed 2019 May 10).

7. National Physician Suicide Awareness Day. Irving (TX): Council of Residency Directors in Emergency Medicine; 2019. Available: www.cordem.org/npsa (accessed 2019 May 10).

8. Brown B. Dare to lead. New York: Penguin Random House; 2018. Available: https://daretolead. brenebrown.com/ (accessed 2019 May 12).

Competing interests: None declared. 